\title{
Standardization or Localization - Organizational Communication on Social Media from a Cultural Perspective
}

\author{
Dr. Maha Alshoaibi*
}

\begin{abstract}
A few years back, globalization and standardization were considered to be the paradigms in the area of international business. But, with changing times, it has lost its lustre considering the branding perspective in global brands. The consumers do not feel connected with highly standardized products and centralized decision-making; most global brands have even stopped any relationship with the typical standardization strategy for communication. Therefore, there is seen a rise in the influence of the localization strategies in communication. A new term is seen emerging lately, and that is 'glocalization' that encourages all the global brands to think internationally while they should act locally. Thus, this paper discusses whether global brands should localize or standardize their communication strategies using social media to be successful. The degree of cultural adaptation of web content impacts the perception of customers on the site's effectiveness. Some consumers prefer localized web content in culturally different areas, whereas some countries prefer localized web content. Keeping all these aspects in mind, organizations need to develop proper communication strategies using social media to be effective in the market and to create a strong brand image.
\end{abstract}

\section{Introduction}

Globally, social networks have emerged as indispensable tools for corporate marketing and communication, but communicating with consumers of various cultures is a tough task. With the changing times, the cultural differences between various nations, regions and ethnic groups are growing (Lillis \& Tian, 2010). With the rising competition in the global markets, international organizations need to effectively manage their knowledge to obtain the financial and opportunity costs that they might have to bear because of a wrong decision.

\footnotetext{
* Assistant Professor, Department of Mass Communication, College of Mass Communication - King Bin Abdulaziz University
} 
While all the cultures present across the globe give importance to their individual beliefs, norms and traditions as it makes them stand out and unique, on the other hand, social media acts as an effective tool that links people across all cultures, regardless of the geographical boundaries or the differences. Chen and Zhang (2010) suggested that time and space have been compressed through the convergence of the new social media and rapid globalization, thus shrinking the whole world into a smaller and highly interactive field (Chen \& Zhang, 2010).

Now people have the ease of interacting with each other across the globe within seconds of sending and receiving messages within seconds. Thus, new social media efficiently does the task of bringing people of varied cultures together in this rapidly expanding "global village". During this kind of intercultural adaptation, people use varied social media types to learn about their host nations' various aspects. They establish and maintain these relationships and stay regularly informed about the vents happening in their home nations. Thus, communication and interaction act as the key factors that impact how new social media affects intercultural adaptations.

In such an environment, all the brands want to project a clear brand identity, but developing an identity that seems appealing to all sensibilities is challenging for organizations. Thus, almost all organizations face the major issues or questions of whether to standardize their external communication or keep it localized? Hence, this research tries to analyze whether to establish a global brand identity for the firm in this standardization-localization debate. It should adopt standardization or localization communication through social media in the international context.

Standardization can be defined as a common approach towards the business that is adopted across the globe. The organizational; adaptation needs a different kind of approach all across different markets (Ang \& Massingham, 2007). Thus, standardization can also be called the technique where a similar marketing mix is used in many countries where the organization operates across the globe in case the firm operates beyond its national boundaries means it internationalizes.

The corporations adopting standardization are known as global corporations, whereas the strategies adopted by them are known as 
standardized or global strategies. On the other hand, global localization or popularly known as adaptation, is the technique where the firm makes modifications to its marketing mix in virtually every nation wherever it operates to cater to every nation's taste, culture, and preferences. Most multinational corporations are seen to be practising global localized strategies for being successful.

Cross-cultural management is considered a vital decisionmaking factor in the case of multinational organizations as it can either prove to be very beneficial for the organization or result in a firm's failure. Therefore critical analysis of the global standardization or localization strategies adopted for external communication for organizations through cross-cultural management in communication on social media is very important. Local localization can win customer loyalty in various cultures; it can also result in dilution of its brand identity. This will, in turn, impact the employee's perception about the organization, thus finally impacting the employees' job satisfaction and job behaviour, thus finally resulting in influencing the overall organizational culture. This "inside-out/outside-in" impact is what this research will explore and how organizational communication can approach this issue.

\section{Research Objectives/Questions}

The provided research is focused on several outputs of marketing and marketing communication, yet the focus of the research is proposed below. Following are the research objectives chosen for the study of the paper.

1. To analyze the importance of localization and standardization in developing brand image.

2. To analyze whether localization or standardization is effective for the success of marketing an organization.

3. Analyzing the impact and importance of the role of social media in the current world for effective organizational communication.

As the objectives point out the importance of both strategies, it is important to focus the research and develop effective research questions. The provided research questions are provided to gain effective outcomes for the study. 
1. What is the importance of localization or standardization in the corporate world?

2. What are the effective methods of localization or standardization used by organizations?

3. How is social media playing an effective role in developing organizational communication?

\section{Research Methodology and Approach}

Research methodology is considered an important aspect while dwelling in research. It helps develop a context or focus on a method for finding information or providing an effective outcome for the study (Snyder, 2019). Literature and past research are considered important sources of methodology for many types of research. It provides wide scope to the study and finds the results based on the past analysis and findings. The provided research focuses on secondary sources and past studies, which have helped collect data and provide analysis.

Similarly, an analytical approach of research has been chosen to develop critical analysis and focuses on providing literary analysis for the study. Analytical research helps find facts and information on the provided topic and focuses on information, which is closely related to the study. This is why the methodological approach chosen is analytical for the study of the provided topic (Snyder, 2019).

\section{Standardization or Localization}

Thorough research has been conducted to investigate the issues related to globalization and localization concerning business, language and culture (Dor, 2004; Gray, 2000). It has been suggested by Dor (2004) that the decision-making process of the consumers is being convicted by native linguistic identity. Therefore the process of 'Englishization" can be termed as the process of economic globalization, whereas the local language can be considered as "local resistance to economic and cultural globalization" (p.97). Issues and tensions exist between economic globalization based upon the Internet and enhanced requirement of local language and culture.

This indicates that the Internet is certainly turning out to be multilingual. The agents of economic globalization have understood the 
importance of getting adapted to the local cultures and language that acts as a key element for organizations to stay competitive. The claims made by Dor (2004) are supported by empirical research that reports that even in the sector of higher education that English highly dominates, the websites are becoming multilingual (Callahan \& Herring, 2012).

Business researchers have also been investigating the local/globalized issue. They have realized that the rapid increase of Internet-based technologies is the cause of supporting the organizations to plan global expansion across different cultures, economies, and political systems (Zhao \& Levary, 2002). Thus, this gives rise to a debate about whether the organizations should adopt a standardized approach towards web communication (that is, a transnational web style) or a localized - specialized approach, that is, should it launch a foreign languages website (Singh, Furrer, \& Ostinelli, 2004). Hence, the two major questions that come up are: Can a social media platform serve as a global marketplace for the organization? Or the organization needs to create separate social media pages for every country where it has a major presence (Gray, 2000).

As such, it has been proposed by researchers that web content on social media that is culturally congruent leads to declining cognitive efforts that is needed for processing the information available on the social media page, thus allowing the users to navigate through the page easily as well as creates more favourable perception towards the brand as well (Luna, Peracchio, \& de Juan, 2002). However, few studies show that there are cross-cultural differences in the social media pages' designs and the response towards the social media pages. Hence they support that country-specific social media platforms or localized forms of organizational communication should be used (Gray, 2000; Luna, Peracchio, \& de Juan, 2002; Simon, 2001; Singh, Furrer, \& Ostinelli, 2004). Just opposite to this view, few other studies show that the impact along with the role played by culture on designing the social media campaign as well as the perception of the social media page is not of much importance for the brand, as they support and propose a standardized approach towards web communication (Yang \& Kang, 2015). 
All the studies mentioned above are contrasting on language usage, and various other studies have done a critical analysis of the localization's graphical aspects. For example, in a research study, significant differences have been noticed between the US and the European nations magazine advertisements and their visual components (Cutler \& Javalgi, 1992). In another study, differences, as well as similarities, have been noticed by the researcher in the design of the websites of the universities of eight nations. They have also noticed that the differences are typically similar to those corresponding to Hofstede's (Hofstede, 1991) cultural dimensions (Callahan, 2005).

Studies conducted in the past have shown that there are visual differences between the US and China, but some results were found to be very contradictory. For example, in a study conducted on the webbased business sites, the Asians recommended that less bold colours should be used (Simon, 1999), on the other hand, the Westerners preferred the bold and bright colours along with many more images so that the web page looks more attractive and modern.

However, in contrast to the above study, the cultural adaptations on the Chinese websites were compared with the US domestic companies websites. It was detected that the Chinese Web Pages used more bold animation, colours, cultural symbols, and traditional themes, thus showing a higher level of contextuality and oneness with nature (Singh, Zhao, \& Hu, 2003). On the other hand, the US websites used much more realistic themes and a lesser amount of imagery and fantasy and more superlatives.

On analyzing the hundred most popular websites, both Chinese and American, there were differences in the characteristics of design and the content that is the site map, help function, and the presence of search engine was common between both of them. However, Chinese websites tend to use more floating banners as well as animated content. These findings, along with debates, indicate that culture is a key variable for developing and designing an online environment that includes social media as well mainly in the case of the online stores' websites that consist of traditional business activities being carried out in the typical cultural backgrounds along with modern Internet technologies like social media platforms. Thus, for branding the products, the visual presentation of information on the Internet, be it 
through websites or social media pages, is crucial (Singh, Furrer, \& Ostinelli, 2004).

Many multinational firms are trying to expand their market share and global presence, increase their profitability and overcome the issues related to the current market saturation Ty continuously tries and seek growth opportunities (Vrontis \& Thrassou, 2007). Organizational communication is a two-way interactive form of communication. The capabilities of both the marketers and the consumers in cross-cultural communication are very important for the firms to succeed (Guang \& Trotter, 2012).

Standardization for international advertising or communication strategy means using similar communication or advertising messages on an international basis. Since the whole international marketplace is turning out to be homogeneous, thus the multinational organizations can plan to standardize their products or services across the globe using standardized communication strategies mainly through the major communication channels like television, movies and the Internet (Wang \& Yang, 2011).

\section{Globalization of Markets}

Starting from the last decennium of the $20^{\text {th }}$-century, globalization has been on rapid growth, and it has had a spectacular impact on brands. Thus new brands are getting born globally, or they get a very quick rollout to form their led or the home countries to the foreign turfs. Many brands are sold traditionally and locally, but they get fazed-out or undergo a quick transition into a global brand name or a new regional brand and subsequent harmonization.

These international or global brands need to assess the potential for standardization of their brands across varied, diverse cultures and societies and find out the various factors that necessitate major and particular brand adaptations along with several prospects for gaining competitive advantage. On the other hand, the local brands' managers also need to know the specific strengths and weaknesses of the strategies of their global competitors so that they can use this knowledge to developing an effective competitive response (Gelder, 2002). 
In an article published in Harvard Business Review, a new and totally global market is fast emerging based on uniform services and products (Levitt, 1983). This phenomenon has been called "Globalization of Markets". He also claims that large-scale organizations no longer emphasize customization of the products or services to deliver globally standardized products. Rather the highly informed customers are now opting for "convergence of tastes"; thus, the firms need to exploit the economies of simplicity, and according to Levitt (1983), the future is for the global organizations that will cater to varied local differences in the taste, but rather go for adopting the strategies that portray as if the whole world is the same.

Therefore, if a company tries to push the cost and price down while pushing the reliability along with quality upwards, while preferring to opt for the suitability, the customers will prefer the worldstandardized products. The best example of such products is that of Coca-Cola, Pepsi and McDonald's. Rather the term globalization was being coined by Levitt only. Although he never mentioned branding, the managers interpreted that he meant that all the transnational or multinational organizations should standardize their products, communication as well as packaging for attaining the position of leastcommon-denominator that would also be very effective across various cultures too (Holt, Quelch, \& Taylor, 2004).

But for some time, standardization is considered a good strategy, but currently, even the globalized products have adopted totally different approaches. For example, Coca-Cola was the best example of standardization. It realized lately that increasing standardized strategy had finished its course, and now the world asks for more flexibility, localization and responsive products. So the next big step after standardization is 'going local' (Ball, 2003).

\section{Global, Local and Glocal Strategies}

Choosing the right marketing strategy for their products is a rising issue for global corporations. The global marketing strategies try to maximize standardization, integration, and homogenization of the activities related to marketing all across the global markets (Kotler, 2009). Several issues are related to marketing strategy that needs to be handled to make the brand successful worldwide. Therefore, marketers 
should try and understand how their brand is fulfilling the needs of their customers and how successful the company's marketing efforts are in individual nations (Kotler, 2009). The following framework has been developed that lays emphasis mainly on the main five marketing strategies for any firm that wants to go global.

Thus it can decide to standardize or localize their product or standardize or localize their communication program or join the two together. There are five possibilities according to this framework ranging from the organizations adopting 'global strategy' (that is, standardization of both communication and product) to development of totally 'local strategy' (that is, customization of both the product as well as the communication program) for every unique market it plans to enter (Schiffman \& Kanuk, 2009). In the middle of the framework lies the two 'mixed strategies', and the last row consists of a combination of strategies and these three strategies are also known as 'glocal strategies'.

\begin{tabular}{|l|l|l|}
\hline PRODUCT STRATEGY & \multicolumn{2}{|c|}{ COMMUNICATION STRATEGY } \\
\cline { 2 - 3 } & $\begin{array}{l}\text { Standardized } \\
\text { Communications }\end{array}$ & Localized Communications \\
\hline Standardized Products & $\begin{array}{l}\text { Global Strategy: } \\
\text { Uniform Product/ } \\
\text { Uniform Message }\end{array}$ & $\begin{array}{l}\text { Glocal Strategy: } \\
\text { Uniform Product/ } \\
\text { Customized Message }\end{array}$ \\
\hline Localized Product & $\begin{array}{l}\text { Glocal Strategy: } \\
\text { Customized Product/ } \\
\text { Uniform Message }\end{array}$ & $\begin{array}{l}\text { Local Strategy: } \\
\text { Customized Product/ } \\
\text { Customized Message }\end{array}$ \\
\hline & Glocal Strategy: \\
& Customized Product/Customized Message \\
\hline
\end{tabular}

Table 1: A Framework for Global marketing and Communication Strategies (Schiffman \& Kanuk, 2009)

Thus, the 'glocal' strategy is a unique idea where marketers think globally while acting locally, which means it is mid-way between global and local strategies as can be seen from the above framework. Glocalization can also be defined as the tempering effects caused by the local conditions on the global pressures that mean the simultaneous existence of both universalizations and particularising tendencies (Khondker, 2004). Friedman (2000) has defined glocalization as the capability possessed by the culture when it faces various stronger cultures, to absorb and adapt to the influences that help in naturally adjusting as well as helps in enriching the culture, to oppose all those things that are not friendly and alien, while compartmentalizing all 
those things, that although being different can be enjoyed and at the same time be celebrated as different (Friedman, 2000).

\section{Rise of Web: Web Communication and Culture}

The Internet is such a unique technology that helps organizations grow and expand globally quickly that too across various cultures, economies, and political systems (Zhao \& Levary, 2002). The best and well-known examples of this fact are eBay, Amazon, Dell, Landsend, and Yahoo and many other organizations that have set up online personal websites locally to reach online customers across the whole world. There is a large surge in targeting global online customers, which has certainly re-ignited the debate whether the firm should standardize or localize their content for communication on the Internet using social media tools (Simon, 2001). Very few studies have analyzed or studied the issues of standardization or localization of the web communications content using social media.

However, there is little evidence from the research studies that show there is the existence of cross-cultural differences while perceiving the content on the web, and thus these studies support that localized web communication strategy is more effective (Fink \& Laupase, 2000; Luna, Peracchio, \& de Juan, 2002; Simon, 2001; Tsikriktsis, 2002). Recently studies conducted on the web content for communication show that firms should emphasize the values, symbols, appeals, as well as the themes that are used for communication content, and all these should be targeted towards the local culture (Kanso \& Nelson, 2002; Singh, Zhao, \& Hu, 2003).

However, on the other hand, there are few studies conducted by Hermans and Shanahan (2002) as well as Yang and Kang (2002) that suggest that the cultural factors do not have any influence on the perception of the customers regarding web communication (Sackmary 1999). Thus, the standardized approach towards web communication is supposed to be better than a localized one.

Even the marketers are unsure whether they should adapt their web content on the websites in foreign countries locally. Therefore, they are rolling out machine translated or standardized websites for various nations where they have a business. For example, in a study, it has been found that out of the 500 US organizations listed on Forbes, 
only 150 firms had developed country-specific pages. For example, some had their WebPages address for New Zealand ending with .nz, while the webpage for Japan ended with .jp, and for Italy, it needed with .it. These 150 company web pages were also localized accordingly for particular nations. At the same time, the rest of the other company websites were simply in English (Singh \& Boughton, 2002).

Forrester research has supported this study that found that amongst all the websites listed on Fortune 100, 67 per cent of websites were in English and thus were standardized. This indicates a shortage and lack of empirical evidence regarding whether to support a standardization approach for web communication (transnational web style) or adopt a localized- specialized approach while launching a web page or a social media page in a foreign country.

There are certain studies that show that web content, be it on the website or social media page, if it is culturally congruent it will result in enhanced navigation as well as a positive attitude towards the firms' product; the four websites that the researchers used for experimenting corroborate this finding (Luna, Peracchio, \& de Juan, 2002). This is because of processing, categorizing, and interpreting the information on the social media or web page through culturally congruent communication that gets facilitated through culturally driven schemas that simply store the whole information abroad, simple and culturally consistent categories (D'Andrade \& Strauss, 1992).

However, this study does not analyze the specific difference between the customers' perception regarding the local company websites, standardized global websites, and the adapted websites for specific nations. These cultural schemas are being shared intersubjectively. Therefore, everyone who is part of the group knows the schemas. Moreover, everyone knows that everybody in the group knows the schemas very well (D'Andrade, 1987).

Culture acts as a lens that is used for viewing the world (McCracken, 1986). It helps in finding the manner we assimilate and apprehend the information surrounding us. It also helps guide our behaviour and actions D'Andrade, 1987). There is a huge body of literature related to how the factors like quality perception (Donthu \& Yoo, 1998; Liu, Furrer, \& Sudarshan, 2001; Mattila, 1999; Tsikriktsis, 
2002), cognitive structures (Aaker, 2000; Aaker \& Maheshwaran, 1997), as well as information processing (McCort \& Malhotra, 1993; Tse, Belk, \& Zhou, 1989) keeps on changing cross-culturally.

It has been found that culturally congruent advertising is more persuasive and powerful than culturally insensitive advertising (Mueller, 1987; Zandpour \& et al., 1994). There are varied studies conducted in the field of information systems that report that there exist cross-cultural differences in the use, adoption, as well as the implementation of IT, related technologies like making social media or web pages and IT systems (Harris \& Davison, 1999; Hunter \& Beck, 2000; Moores \& Gregory, 2000). Moreover, the variation in Internet users worldwide is also attributed to being majorly associated with foreign consumers' cultural beliefs (Park, 2001).

When testing the generalization of Fishbein's Intention Model, it has been seen that the collectivist tendencies seen in the Korean consumers make them believe that the social influences are more important as compared to the personal attitudes of the consumers for finding out the consumer's behaviour intentions (Lee \& Green, 1991). On similar grounds, Chinese consumers rely more on consensus-related information related to attributes for evaluating any product (Aaker \& Maheshwaran, 1997). Therefore, it can be seen that cultural analysis is linked with the mental process of any individual consumer (Strauss \& Quinn, 1997).

Thus, based on the above findings from various studies, it can be proposed that consumers who share the same type of cultural schemas are more likely going to evaluate the local web pages or social media pages as well as the websites that have adapted to the localized culture. Additionally, they are likely to evaluate content presented either on web site or on social media pages that are culturally congruent in their local language rather than searching for standardized websites and have endorsed information in the English language only.

\section{Localization of Website}

The new era of communication through electronics is growing rapidly and has opened many cross-cultural communication platforms, for example, individual screens of websites or social media pages. Thus, the websites are also getting localized, which is a very complex process 
as it has normal constraints attached to it and several goals related to translation. However, localization is different from non-hypertext translation as the translatable elements should be identified in localization. Also, tools are required for translating, non-linearity of translatable elements, how the process of translation is started, and coordinated along with the limit up to which the changes will be made (Cheng, 2000). The making of websites or WebPages is based on the dynamics of one-to-many products; therefore, cost efficiency is achieved through website localization. A central version of the website is prepared so that most of the issues related to translation could be avoided even before they arise.

This type of preparation is dubbed or called 'internationalization' in the sector of software localization, which entails making sure that the least possible culture-specific features are introduced in the generalized site because these characters are the ones that will cause issues downstream later on. Therefore, an internationalized site is the one that is completely neutral and functional and is made in such a manner that the localization teams, if need be, can add elements like colours, images, or references etc. - thus, making the site highly attractive for the consumers residing in specific cultural locales (Corte, 2002).

On the other hand, localization of the website means reducing the cultural elements during the internationalization process; therefore, the versions move into particular target languages, they will have to, later on, add certain features that are considered specific for the target culture (O'Hagan \& Ashworth, 2002). Thus, it can be said that the web content is localized by adapting the features so that they suit a specific locale or a particular market segment defined through particular criteria like currency, language, educational level, income bracket, mainly depending upon the nature of communication. Some localized technical elements include time and date formats, calendar settings; currency formats; number formats; name formats; telephone number formats; address formats, units of measure, etc. (Esselink, 2000).

The degree of localization of the web content on websites is related to the cultural implications of the brands' marketing strategies and the presence of several languages. There are five degrees of localization that are: 'standardized' (one website for all the nations); 
'semi-localized' (one site delivering information about several nations); 'highly localized' (translations in addition to country-specific adaptations); 'culturally customized' (a completely new site plunged deep in the target culture) (Nitish \& Pereira, 2005).

For example, the basic home page of Google that looks the same in all the versions of different languages can thus appear to be an extreme case of standardization that tries to maintain the company's image for developing a brand 'Google'. But in Japan or Korea, this homepage is considered incomplete or devoid of any substance. The users are acclimatized to using the web pages crowded with several invitations for joining certain exciting things.

Therefore, in such nations, the local search engines or Yahoo! is much more popular than Google. Thus, Google has adopted a standardization strategy that it does not change rather offers its users to build their homepages on Google, where they can add as many options or things they want. Thus, the resulting localization can be considered a combination of standardization and cultural customization (O'Hagan \& Ashworth, 2002).

On comparing the websites present in a relatively small local (the Slovene language) with the ones that are written in English for global markets, it has been found that the global websites lay more emphasis on the user, thus involving a second person, trying mostly to fulfil the needs of the user thus representing themselves with a 'human face.' On the other hand, the local sites from Slovenia mainly emphasize the achievements of the organizations and the products, thus utilizing more technical registers and insisting on modern technology. Thus, showing deep-rooted cultural differences is not deeper enough to spread the professional culture of marketing (Limon, 2008).

\section{Power of Social Media}

Social Media is a powerful communication tool used by many organizations for effectively engaging their customers through a single and well-coordinated effort. Social Media helps drive a high level of awareness and bard loyalty for the firm's diverse and very popular product line, enhancing its reputation for power and performance across various communities and cultures. For example, in Honda, social media managers explore ways to better coordinate social initiatives for their 
distinct audiences across the European continent. Honda Motor Company operates across 29 countries and has a diverse line of products; thus, leveraging social media for engaging the fans and its followers across various geographic regions and multiple products and languages is a major challenge for the company.

But it wanted to coordinate the social media efforts while properly aligning the stakeholders, unifying the data sets and establishing governance policies. Hence, it required a much more integrated approach for creating and managing social content and measuring social interactions. Honda Europe uses Adobe Social to reduce costs, coordinate the marketing campaigns, and enforce brand governance using a single social media platform. Adobe Social helps in creating a single underlying application for uploading photos that can be easily and very rapidly uploaded across the various markets at the same time. The App Audiences feature of Adobe Social helps deliver a localized version of the app to the user based on the language chosen by him on the user interface on Facebook.

This allows brand consistency and promotes a globally coordinated brand campaign across various markets, thus decreasing the production costs and reducing the time spent on marketing. Thus, social media platform like Facebook helps the firm in centralizing the whole content management for communication. Thus, helping create, deliver, and track social content in the form of a single platform that help in making much more efficient use of resources and make fastpaced delivery of all the details regarding the latest Honda services and products.

These types of communication campaigns used by organizations through social media help save thousands of Euros through effective campaigns and drive the bottom-line results. Although using social media platforms helps improve social media quality and brand consistency across the markets, there are challenges as well as centralizing social media control and simultaneously improving local creativity and shifting the focus from tactics towards the strategy for the strategy social media marketers.

Social media platforms like Facebook, Twitter, etc., help target the specific audience based on language, psychographic data, and 
geography, which in turn helps the local marketers reach the followers and the customers through the content that resounds the local interest with the firms' products. This way, the organizations can understand in a better manner which communities or cultures are more inclined towards which product; thus, they can develop campaign strategies and content that enhance more customer engagement.

\section{POI Localization Using Social Media}

Points of Interests (POIs) are defined as the main part of eth geographical databases and location-based services. The coverage and quality of POIs ensure the success of various applications depending upon geographies, such as location-based services (LBS), navigation systems, or mapping interfaces. Since these POIs are added by the domain experts who have either browsed the current resources or have visited physical locations, thus the final databases are very accurate. Still, their updating and constitution come at a very high cost (Rae et al., 2012).

The success of social media gives rise to largely geotagged datasets of multimedia, and they are being used for data extraction related to geographic locations. Flickr data has been pioneered for extracting the POI names, locations, and popularity by using the spatial burst detection technique (Rattenbury et al., 2007). In a follow-up study, researchers have emphasized using multimedia clustering to produce diversified and representative visual representations of POIs (Kennedy \& Naaman, 2008). One more major study shows that the socially representative clusters are more reliable and relevant than others.

Using a geotagged photos as datasets when we try to find out the POI location that is available on social media, mainly three issues arise that finally lead to wrong results and these issues are: the photos are being kept at the point where they have been taken, this point is mostly very far away from the true POI location; errors related to geotagging might occur, mainly because the whole process occurs manually as the users do not place the photo mostly wherever they are taken; and thirdly there is no control over the user-generated content. Thus, just a small fraction of photos that are tagged with POI names can find it. Thus, visual cues are very vital for localization as compared to 
textual cues. Considering these issues in POIs, localization seems to be problematic for organizations to adopt for communication using social media.

\section{Localization: Does it Work? Or Standardization}

It is observed that localization does not work as always desired for the brands and that too mainly in the emerging markets. Thus, the marketers need to know how far they should localize their products and whether the process of localization will work for them. The adaptation of the services or products or the offerings of a firm to meet the cultural, language, other specific needs of the particular target markets is called localization (Wise Geek, 2012). During the early $20^{\text {th }}$ century, standardization and globalization were the most common trends of business across the globe that helped in leveraging the scale economies.

However, the era of standardization or globalization is about to end because of diminishing returns about consumer products. It has been mentioned in many studies that standardization is necessary for products/services to maintain their values as well as for creating brand identity. But on the other hand, it is seen that standardization acts as a barrier to innovation, differentiation, and customization of the product. Therefore, introducing a little local flavour is much in trend amongst the marketers.

But determining the degree of localization is a tough task. Many global brands are seen to be practising localization for quite some time. For example, McDonald's has certain meals that are served only in India. In contrast, some of the models of Volkswagen cars are found only in China, and these localized products cannot be found outside these particular nations. But too much localization can also diminish the product's global identity, thus degrading the tag of "global brand". There are many cases where global brands try and localize their product's value proposition. Still, they have to fight to balance the needs of localization and preserve the global brand name.

The best example that can be quoted here is McDonald's as it aims to customize its marketing campaigns in various nations while retaining its core values that are "favourite place for eating out". In 2011 it introduced a new spicy range in India of various products and a new advertising campaign for communication that had a tagline of "How 
spicy is McSpicy?" (Sayal, 2011). This was done to depict The McDonalds brand as a youthful brand that caters to the preferences and tastes of its young customers. Thus, the new menu and the advertising campaign used a social media mix and outdoor branding and QR codes catering to the tastes and preferences of the Indian customers (Sayal, 2011).

On the other hand, in US markets, McDonald's relied on the social media platform to depict the real-life farmers and the ranchers that are the major suppliers of ingredients to McDonald's. Thus, the testimonials and clippings sent out a very strong message to its target audience that McDonald's is not just related to fast food. Rather it's about real food-born on earth, thus highlighting the factor of 'authenticity' (O'Brien, 2012).

\section{Conclusion}

From the above studies and the evidence, it is quite clear that global brands need to adopt efficient and effective communication for global brands to establish their brand identity across various cultural grounds or countries. Social media can act as a powerful tool that will certainly help channel the resources and reduce the production cost for the firms. But whether to standardize or localize an organization's communication strategy on social media according to different cultures is a big question. As can be seen that the current trend is of localization of products and services while standardization is losing its popularity. Too much standardization can lead to the stagnation of the brand. While too much localization can result in higher production costs and centralization or decentralization issues.

Thus, over-localization can be a threat to the fundamental brand appeal of international brands. Most of the firms are adopting localization strategies for communicating with the customers as it is a simple, easy, and fast tool for communication. But the firms need to localize to an extent so that they do not lose their brand identity and brand image. The products should be tuned according to the expectations of the target audience. Therefore, while designing the strategy for localization, more attention should be paid to the language, subculture of the target audience, and the nature of the service or product. The brand should study whether there are any types of related 
linguistic quirks and cultural differences, which should be analyzed. The final strategy that emerges as the best one for global brands for communication using social media is 'glocalization', a combination of standardization and localization. 


\section{References}

Aaker, J. L. (2000). Accessibility or diagnosticity? Disentangling the influence of culture on persuasion processes and attitudes. Journal of Consumer Research, 26(4), 340-357.

Aaker, J. L., \& Maheswaran, D. (1997). The effect of cultural orientation on persuasion. Journal of consumer research, 24(3), 315-328.

Ang, Z., \& Massingham, P. (2007). National culture and the standardization versus adaptation of knowledge management. Journal of Knowledge Management, 11(2), 5-21.

Ball, D. (2003). International Business: The Challenge of Global Competition. Boston: Mcgraw Hill.

Callahan, E. (2005). Cultural similarities and differences in the design of university web sites. Journal of computer-mediated communication, 11(1), 239-273.

CALlAHAN, E., \& HERRING, S. C. (2012). Language Choice on University Websites: Longitudinal Trends. International Journal of Communication, 6 , $322-355$

Chen, G. M., \& Zhang, K. (2010). New media and cultural identity in the global society. In Handbook of research on discourse behavior and digital communication: Language structures and social interaction (pp. 795-809). IGI Global.

Cheng, S. (2000). 'Globalizing an e-Commerce Web Site. Philadephia: John Benjamins Publishing Company.

Corte, N. (2002). Localization and internationalization of websites. Tradumàtica , (1).

Cutler, B. D., \& Javalgi, R. G. (1992). A cross-cultural analysis of the visual components of print advertising: The United States and the European Community. Journal of Advertising Research, 32(1), 71-80.

D'Andrade, R. (1987). A folk model of the mind. In D. Holland, \& N., Quinn. Cultural models in language and thought, (pp.112-148) Cambridge University Press.

Donthu, N., \& Yoo, B. (1998). Cultural influences on service quality expectations. Journal of service research, 1(2), 178-186.

Dor, D. (2004). From Englishization to imposed multilingualism: Globalization, the Internet, and the political economy of the linguistic code. Public Culture, 16(1), 97-118.

Esselink, B. (2000). A practical guide to localization (Vol. 4). John Benjamins Publishing.

Fink, D., \& Laupase, R. (2000). Perceptions of Web site design characteristics: a Malaysian/Australian comparison. Internet Research: Electronic 
Networking Applications and Policy, 10(1), 44-55.

Friedman, T. L. (2000). The Lexus and the olive tree: Understanding globalization. Farrar, Straus and Giroux.

Gelder, S. (2002). GENERAL STRATEGIES FOR GLOBAL BRANDS. Brand Meta. Retrieved from http://www.decimo.no/Artikler/65GlobalBrandStrategy.pdf

Gray, R. (2000). Make the most of local differences. Marketing, 27-28.

Guang, T., \& Trotter, D. (2012). Key issues in cross-cultural business communication: Anthropological approaches to international business. African Journal of Business Management, 6(22), 6456-6464.

Harris, R. W., \& Davison, R. (1999). Anxiety and Involvement: Cultural Dimensions of Attitudes Toward Computers in Developing Societies. Journal of Global Information Management (JGIM), 7(1), 26-38.

Hermans, C. M., \& Shanahan, K. J. (2002). The Reification of Levitt: Advertising preferences for Mexican and American online consumers. Developments in Marketing Science, 25, 147-147.

Hofstede, G. (1991). Culture and organizations: Software of the mind. London : McGraw Hill.

Holt, D. B., Quelch, J. A., \& Taylor, E. L. (2004). How global brands compete. Harvard business review, 82(9), 68-75.

Hunter, M. G., \& Beck, J. E. (2000). Using repertory grids to conduct cross-cultural information systems research. Information Systems Research, 11(1), 93-101.

Kanso, A., \& Nelson, R. A. (2002). Advertising localization overshadows standardization. Journal of Advertising Research, 42(1), 79-89.

Kennedy, L. S., \& Naaman, M. (2008, April). Generating diverse and representative image search results for landmarks. In Proceedings of the 17th international conference on World Wide Web (pp. 297-306).

Khondker, H. H. (2004). Glocalization as globalization: Evolution of a sociological concept. Bangladesh e-journal of Sociology, 1(2), 1-9.

Kotler, P. (2009). Marketing Management. Harlow, England: Pearson Prentice Hall Publishing.

Lee, C., \& Green, R. T. (1991). Cross-cultural examination of the Fishbein behavioral intentions model. Journal of international business studies, 22(2), 289-305.

Levitt, T. (1983). The Globalization of Markets. Harvard Business Review. Retrieved from https://hbr.org/1983/05/the-globalization-of-markets

Lillis, M., \& Tian, R. (2010). Cultural issues in the business world: An anthropological perspective. Journal of Social Sciences, 6(1), 99-112.

Limon, D. (2008). Company websites, genre conventions and the role of the 
translator. Cultus, 1(1), 56-69.

Liu, B. S. C., Furrer, O., \& Sudharshan, D. (2001). The relationships between culture and behavioral intentions toward services. Journal of service research, 4(2), 118-129.

Luna, D., Peracchio, L. A., \& de Juan, M. D. (2002). Cross-cultural and cognitive aspects of web site navigation. Journal of the academy of marketing science, 30(4), 397-410.

Mattila, A. S. (1999). The role of culture in the service evaluation process. Journal of service research, 1(3), 250-261.

McCort, D. J., \& Malhotra, N. K. (1993). Culture and consumer behavior: toward an understanding of cross-cultural consumer behavior in international marketing. Journal of International Consumer Marketing, 6(2), 91-127.

McCracken, G. (1986). Culture and consumption: A theoretical account of the structure and movement of the cultural meaning of consumer goods. Journal of consumer research, 13(1), 71-84.

McDonald's 'McSpicy' Marketing Campaign in India. (2011, April). (Case Code: MKTG288). ICMR India.

Moores, T. T., \& Gregory, F. H. (2000). Cultural problems in applying SSM for IS development. Journal of Global Information Management (JGIM), 8(1), 1419.

Mueller, B. (1987). Reflections of Culture: An Analysis of Japanese and American Advertising Appeals. (Paper presented at the Annual Meeting of the Association for Education in Journalism and Mass Communication (69th, Norman, OK, August 3-6, 1986). Retrieved from https://files.eric.ed.gov/fulltext/ED271776.pdf

Nitish, S., \& Pereira, A. (2005). The culturally customized web site: Customizing web sites for the global marketplace. Burlington, MA: Elsevier

O'Brien, K. (2012, May 4). How McDonald's came back bigger than ever. The New York Times. Retrieved from https://www.nytimes.com/2012/05/06/magazine/how-mcdonalds-cameback-bigger-than-ever.html

O'Hagan, M., \& Ashworth, D. (2002). Translation-mediated Communication in a Digital World: Facing the Challenges of Globalization and Localization (Vol. 23). Multilingual Matters.

Park, H. (2001). Cultural impact on internet connectivity and its implication. Journal of Euromarketing, 10(3), 5-22.

Rae, A., Murdock, V., Popescu, A., \& Bouchard, H. (2012, August). Mining the web for points of interest. In Proceedings of the 35th international ACM SIGIR conference on Research and development in information retrieval (pp. 711- 
$720)$.

Rattenbury, T., Good, N., \& Naaman, M. (2007, July). Towards automatic extraction of event and place semantics from flickr tags. In Proceedings of the 30th annual international ACM SIGIR conference on Research and development in information retrieval (pp. 103-110).

SACKMARY, B. (1999). Cultural Patterns of World Wide Web Business Sites: a Comparison of Mexican and US. Companies. In Seventh Cross-Cultural Consumer and Business Studies Research Conference, Cancun, Mexico, December 12-15, 1999 (Vol. 2).

Sayal, S. (2011, April 6). 'How spicy is McSpicy?' quizzes McDonald's. afaqs. Retrieved from https://www.afaqs.com/news/digital/30168 how-spicy-ismcspicy-quizzes-mcdonalds

Schiffman, L., \& Kanuk, L.L. (2009). Consumer behavior. New Jersey: Pearson Prentice Hall Publishing.

Simon, S. J. (1999, December). A cross-cultural analysis of web site design: an empirical study of global web users. In Seventh Cross-Cultural Consumer and Business Studies Research Conference. Cancun, Mexico.

Simon, S. J. (2000). The impact of culture and gender on web sites: an empirical study. ACM SIGMIS Database: The Database for Advances in Information Systems, 32(1), 18-37.

Singh, N., \& Boughton, P. D. (2002). Measuring web site globalization: A crosssectional country and industry level analysis. In American Marketing Association. Conference Proceedings (Vol. 13, p. 302). American Marketing Association.

Singh, N., Furrer, O., \& Ostinelli, M. (2004). To localize or to standardize on the web: empirical evidence from Italy, India, Netherlands, Spain, and Switzerland. Multinational Business Review, 12(1), 69-87.

Singh, N., Zhao, H., \& Hu, X. (2003). Cultural adaptation on the web: A study of American companies' domestic and Chinese websites. Journal of Global Information Management (JGIM), 11(3), 63-80.

Snyder, H. (2019). Literature review as a research methodology: An overview and guidelines. Journal of business research, 104, 333-339.

Strauss, C., \& Quinn, N. (1997). A cognitive theory of cultural meaning (No. 9). Cambridge University Press.

Tse, D. K., Belk, R. W., \& Zhou, N. (1989). Becoming a consumer society: A longitudinal and cross-cultural content analysis of print ads from Hong Kong, the People's Republic of China, and Taiwan. Journal of consumer research, 15(4), 457-472.

Tsikriktsis, N. (2002). Does culture influence web site quality expectations? An 
empirical study. Journal of service research, 5(2), 101-112.

Vrontis, D., \& Thrassou, A. (2007). Adaptation vs. standardization in international marketing-the country-of-origin effect. Innovative marketing, 3(4), 7-20.

Wang, X., \& Yang, Z. (2011). Standardization or adaptation in international advertising strategies: The roles of brand personality and country-of-origin image. Asian Journal of Business Research, 1(2), 25-31.

Wise Geek. (2012). What is Localization? WiseGeek.

Yang, K. C., \& Kang, Y. (2015). The Influence of Cultural Factors on Consumers' Reactions to Internet Advertisements. In Proceedings of the 2002 Academy of Marketing Science (AMS) Annual Conference (pp. 148-153). Springer, Cham.

Zandpour, F., Campos, V., Catalano, J., Chang, C., Cho, Y. D., Jiang, S. F., ... \& Hoobyar, R. (1994). Global reach and local touch: Achieving cultural fitness in TV advertising. Journal of Advertising Research, 34(5), 35-64.

Zhao, H., \& Levary, R. R. (2002). Evaluation of country attractiveness for foreign direct investment in the e-retail industry. Multinational Business Review, 10(1), 1-10. 